\title{
CRM Implementation in Lebanese SMEs: Descriptive Analysis
}

\author{
Lena Saleh ${ }^{1} \&$ Laura El Saheli ${ }^{1}$ \\ ${ }^{1}$ Faculty of Economic Science and Business Administration, Lebanese University, Beirut, Lebanon \\ Correspondence: Lena Saleh, Faculty of Economic Science and Business Administration, Lebanese University, \\ Beirut, Lebanon. E-mail: saleh-lena@hotmail.com
}

Received: August 7, 2018

Accepted: October 29, 2018 Online Published: January 24, 2019

doi:10.5539/ijms.v11n1p76

URL: https://doi.org/10.5539/ijms.v11n1p76

\begin{abstract}
SMEs and entrepreneurship are the foundational drivers for the creation of economic value, source of innovation, employment and wealth generation across the globe (Inventis, 2014). The beauty service industry is one of the most flourishing industries in contemporary Beirut, the capital of Lebanon, as versatile demands from men and women have catered to this uplifting growth. A national scandal, however, lead to the suspension of several beauty centers, and conveyed a challenge for competitive small-medium enterprises (SME) to sustain relationships with customers over the long-run. The aim of this study was to discover the extent to which CRM is implemented in SMEs, using the case of beauty centers in Beirut, Lebanon. The study employed a quantitative approach where data was collected by means of a questionnaire, from a sample of 103 customers. Four variables, as components of CRM, were measured in this study. Results of the statistical analysis found that SMEs in Lebanon implement CRM strategy to a good extent. This research provides recommendations for strategically improving relationship-oriented practices in Lebanese SMEs, particularly in the beauty sector.
\end{abstract}

Keywords: small-medium enterprise (SME), customer relationship management (CRM), beauty center in Lebanon

\section{Introduction}

Over $90 \%$ of enterprises currently active in the economy can be categorized as SMEs. SMEs and entrepreneurs in Lebanon operate in a complex environment of interrelated elements which impact the ease and speed at which new ventures can be established and transformed into sustainable and competitive businesses (Inventis, 2014). In such a customer-oriented era, SME can no longer remain the strategies in product orientation; instead, they are required to create and deliver value to targeted customers at a profit. Thus, SME should build relationships with customers for economic reasons. The business generates two key benefits from managing relationship with customers. The first is that less money has to be spent on replacing customers, relative to research, strategic analysis, time, and creative work and the second is that as tenure grows, suppliers gain a better understanding of customer requirements, and as a result, they are more capable of identifying and satisfying the requirements a lot faster. But does CRM can be implemented by any company? The banking industry has implemented CRM widely. They want CRM for its analytical capability to help them to manage customer defection rates and to enhance cross-sell performance (Buttle, 2007). CRM takes many forms and addresses many relationships issues. Four contexts are considered by researchers: banks, automobile manufacturers, high tech companies and consumer goods manufacturers. Thus the implementation of CRM in the context of SME is a relevant field of research. The researcher explores the degree to which Lebanese SMEs implement CRM, using the case of beauty centers, from the customer's perspective.

\section{Literature Review}

\subsection{Defining SME}

Institutions and governments in the public and private sector all over the world emphasize that standard definitions of SMEs are difficult to form, especially since there are three categories of enterprises (micro, small, $\&$ medium) that contain a large gap in terms of organization, structure, and ways of functioning in the market (Rostek, 2015). Therefore, institutions develop their own definitions that suit their requirements. The European Commission (2001) defines an SME as an enterprise that employs fewer than 250 people, and is considered to have annual sales of less than $£ 50$ million (Analoui \& Karami, 2003). Since statistical information is scarce in Lebanon, there is a lack of a formal definition for SMEs in this region. The World Bank's MSME database 
estimates that before the final war in Lebanon, approximately 192, 569 SMEs were operating in Lebanon, which effectively translates into a rate of 47.2 MSME per 1000 people (MSME database, World Bank, 2006). SMEs face a lot of challenges that significantly delay their progress, growth and eventually their contribution to economic development. SMEs face the unique problems of uncertainty, innovation and evolution. Small enterprises have limited resources related to finance, time, marketing knowledge, and expertise (Reijonen \& Laukkanen, 2010). Thus, Marketing practices in small enterprises differ from those in large enterprises due to certain constraints. However, because of their smaller scale, SMEs have a tendency to form intimate, more personal relationships with customers than larger organizations, as found in several studies in the banking and finance sector (Ozgener \& Iraz, 2006; Kirmaci, 2012; Ndubisi et al., 2007; Shen \& Russell, 2007). This involves creating the optimum experience for the customer every time that they interact with the company (Scarborough, 2011).

\subsection{Defining CRM}

A collection of definitions has been reviewed from several scholars to better understand the meaning of CRM in business. Scholarly writers differed among each other while formulating a specific definition for it. According to Ozgener and Iraz (2006), CRM is a cross-functional process that provides personalized treatment to the most valuable, or profitable, customers in order to increase customer retention and the effectiveness of marketing activities. According to (Shen \& Russell, 2007), CRM embodies the modern paradigm of relationship management, and leverages information technology (IT) to acquire customers, understand and satisfy their needs and expectations, and maintain long-term relationships through retention programs that build customer loyalty. This definition for CRM reflects on its ability to use technology to deal with customers. Swift (2000), as cited in Soliman (2011), defined CRM as: "a method of understanding the customer behaviour through intense communication" in order to improve performance, which is represented in attracting the customer, retaining them, and increasing their loyalty and profitability. In this definition, CRM is regarded as a communication mechanism on the part of the organization that is used to understand customer behaviour. Peelen and Beltman (2013) define CRM, based on Gartner (2004), as an IT enabled business strategy that is organized around customer segments, fosters customer-satisfying behaviours, and implements customer-centric processes in order to optimise profitability, revenue, and customer satisfaction. In other words, CRM is an interactive process and directs all its business activities directed towards initiating, establishing, maintaining, and developing successful long-term relational exchanges. Since there are various points of view related to the CRM concept, writers have not reached an agreement on defining it. With the aim of summarizing the most important concepts of CRM, Zablah et al. (2004) demonstrates a five-point view to define CRM. Table 1 below demonstrates the most important factors among the points of view. 
Table 1. The five-point view to define CRM

\begin{tabular}{|c|c|c|c|}
\hline Point of View & Description & Success Requirement & Concept \\
\hline The process & $\begin{array}{l}\text { Improves the relationships } \\
\text { between the seller and the } \\
\text { customer. Relationships should be } \\
\text { strong and manageable. }\end{array}$ & $\begin{array}{l}\text { The organization should be able to } \\
\text { discover the customer's personal } \\
\text { desires, and respond to them } \\
\text { accordingly }\end{array}$ & $\begin{array}{l}\text { CRM is creating and enhancing the } \\
\text { engagement relationships with the } \\
\text { external parties, the agents, and the } \\
\text { end-consumers. }\end{array}$ \\
\hline The strategy & $\begin{array}{l}\text { The customer's lifetime value } \\
\text { determines the amount and kind } \\
\text { of resources that the organization } \\
\text { can invest in a relationship. }\end{array}$ & $\begin{array}{l}\text { The organization must assess its } \\
\text { relationship with customers on a } \\
\text { continuous basis. Priorities should be } \\
\text { assigned with regards to dealing with } \\
\text { the customer on the basis of quantitative } \\
\text { profitability during the customer's life } \\
\text { period. }\end{array}$ & $\begin{array}{l}\text { CRM is a company's investment in } \\
\text { customers who are expected to be } \\
\text { valuable to the organization, and less } \\
\text { investment in the customers that do } \\
\text { not bring value to the company. }\end{array}$ \\
\hline The philosophy & $\begin{array}{l}\text { Customer retention can be } \\
\text { achieved when the organization } \\
\text { focuses on establishing and } \\
\text { maintaining relationships. }\end{array}$ & $\begin{array}{l}\text { The customer should be the center of } \\
\text { attention in the organization. The } \\
\text { organization should be founded on the } \\
\text { scope of understanding the customer's } \\
\text { changeable needs. }\end{array}$ & $\begin{array}{l}\text { CRM is not a temporary project, but } \\
\text { a work-philosophy that aims to put } \\
\text { the customer as the center of } \\
\text { attention in the organization. }\end{array}$ \\
\hline The ability & $\begin{array}{l}\text { Profitable and long-term } \\
\text { relationships only happen when } \\
\text { organizations are able to } \\
\text { customize their behaviour } \\
\text { continuously toward every } \\
\text { customer. }\end{array}$ & $\begin{array}{l}\text { The organization must have a set of } \\
\text { tangible and intangible resources that it } \\
\text { can use to continuously modify its } \\
\text { behaviour according to the customer in a } \\
\text { flexible manner. }\end{array}$ & $\begin{array}{l}\text { CRM is the desire and ability of the } \\
\text { organization to customize its } \\
\text { behaviour towards every customer } \\
\text { based on the information that the } \\
\text { customer provides and what the } \\
\text { organization knows about that } \\
\text { customer, or can make from the } \\
\text { information provided. }\end{array}$ \\
\hline The technology & $\begin{array}{l}\text { Knowledge management and } \\
\text { feedback are the main resources } \\
\text { that an organization needs in } \\
\text { order to establish profitable and } \\
\text { long-term relationships with the } \\
\text { customer. }\end{array}$ & $\begin{array}{l}\text { The organization must be pointed } \\
\text { towards a functional method, and the } \\
\text { user's acceptance of the technology } \\
\text { applied by the organization. This way } \\
\text { the organization can confirm customer } \\
\text { knowledge and reaction management. }\end{array}$ & $\begin{array}{l}\text { CRM is a technology that is used to } \\
\text { actively put together the } \\
\text { organization's sales systems, } \\
\text { marketing systems, and information } \\
\text { systems to establish quality } \\
\text { relationships with customers. }\end{array}$ \\
\hline
\end{tabular}

Note. Source: Zablah et al., (2004), 475-489.

In consideration of the above table, the researcher constructed a definition that suits the goal of the present study. This definition is: CRM is a relationship-oriented strategy that applies people, processes and technology to establish, strengthen, and sustain long-term mutually beneficial relationships with customers. CRM is committed to helping a business deliver value and the right solutions to customers while maximizing business performance and outrunning competitors.

\section{Methodology}

In this study, the quantitative research method was selected. This method was the most suitable as it involves the empirical investigation of the research question using scientific methods. The researcher was able to quantify the problem by generating a large quantity of numerical data, or data that can be transformed into useable statistics, to answer the research question (Johanek, 2000). The quantitative method was appropriate for several reasons. The quantitative approach served the objective of the research, which was to discover to what extent were SMEs implementing CRM, from the customer's perspective. The researcher was able to gather a large amount of data to analyse it statistically, with very little bias involved. The data derived was measurable so as to generate facts and uncover patterns in research. Since the data provided in the quantitative study was numeric, the researcher was able to conduct statistical tests to make statements using descriptive statistics and inferential statistics. Through statistical analysis the researcher was able to develop important facts from research groups including preferences, trends, differences between groups, and other demographic facts.

\subsection{Variables}

According to the literature review, there are many "building blocks" or elements that makeup CRM. However, after an extensive review of literature, the researcher developed the following four elements to apply to the study: customer experience, employee behaviour, value proposition, and relationship development. The definition for each variable will be discussed below. 


\subsubsection{Customer Experience}

Customer experience is essential to creating value (Prahalad \& Krishnan, 2008). One of the main strategic objectives in CRM is to obtain a comprehensive view of customer needs, and to anticipate and react to changes in those needs by using targeted activities at every touch point (Ozgener \& Iraz, 2006; Peelen, 2013)

\subsubsection{Employee Behaviour}

Employees have a major impact on the creation, development, and maintenance of customer relationships. For that reason, during any sort of purchase, particularly a service, customers and employees are deemed "inseparable" (Buttle, 2004). The importance of employee behaviour is prominent in the service industry because there is direct interaction with the customer.

\subsubsection{Value Proposition}

Perception about value is subjective, and thus, differs from one person to another. Since this is the case, organizations must customize their offerings in order to satisfy the needs and expectations of their customer base, and target the segments that are most profitable (Reijonen \& Laukkanen, 2010). Ideally, a customer-centric organization provides a solution to customers through a process of customization (Peelen \& Beltman, 2013). Customization links the customer to the firm's understanding of underlying needs and expectations.

\subsubsection{Relationship Development}

An enterprise that seeks to strengthen their customer base not only offers customized service, but continuously develops the relationship with their customers. According to Long et al. (2003), the most important activity in relationship development is to monitor the process itself. It involves understanding the customer's changing needs and expectations, and then organizing tactics to ensure satisfaction and retention.

\subsection{Design of the Questionnaire}

A questionnaire was the most suitable research instrument to collect quantitative data for the purpose of the study. This instrument allowed the data to be analyzed objectively, and the researcher was able to collect a large amount of information from a large number of people in a short period of time. The questionnaire started with the customer's profile and continued towards specific questions related to variables of the study. The profile section identified the customer's gender, age, marital status, the name of the beauty center they visit, and how often they visit it. The customer' social class, occupation, how much they typically spend for a treatment at the beauty center, and the type of service they purchase were also items of interest in the customer's profile. The next section of the questionnaire contained specific questions pertaining to the variables of the study. The items in the questionnaire for each variable were based on a sufficient literature review of various studies. For the first variable, customer experience, the questionnaire contained eleven items (i.e., appointment reminder, channel of reminder, appointment follow-up, channel of follow-up, promotion information, channel of promotion information, welcoming reception area, refreshing ambiance, waiting time, hospitality, available help). Employee behavior was the second variable and contained eight items (i.e., friendliness, politeness, listening to needs, knowing preferences, quick response, knowledge of equipment, expert in work, and cooperativeness). Value proposition, the third variable, contained six items (i.e., fair price, product quality, equipment quality, convenience of location, service-preference fit, fulfillment of needs). Relationship development was the fourth variable contained ten items (i.e., record of personal information, record of visits, presence of a loyalty-card program, complaint, means of reporting complaint, means of handling complaint, satisfaction of solution for complaint, feedback request, channel of feedback request, seriousness for feedback).

\subsection{Research Sample}

The target population was customers of beauty centers in Beirut, Lebanon. The researcher obtained data from 110 customers of beauty centers, however voided 7 questionnaires which were incomplete and insufficient for providing data to the study. The 103 respondents consisted of males and females. The age category was open to respondents under 18 , between 18 and 30 , and above 30 . The age range was open given the commonality of consumption for beauty-related services among people.

\section{Results}

\subsection{Descriptive Statistics}

This section focuses on descriptive statistics derived from the questionnaire. The first subsection discusses the demographic characteristics, using data derived from the "profile" section. The second subsection presents the results pertaining to the extent to which CRM is implemented in beauty centers, based on the customer's perspective. 


\subsubsection{Demographic Characteristics}

The demographic characteristics of the sample from which the data was collected are presented below. The study contained a total of 103 respondents that were customers of beauty centers in Beirut. Table 2 shows the frequency and percentages pertaining to the characteristics of the sample.

Table 2. Demographic characteristics of the research sample

\begin{tabular}{|c|c|c|c|c|}
\hline Variable & \multicolumn{2}{|c|}{ Classification } & Frequency & Percentage \\
\hline \multirow[t]{2}{*}{ Gender } & \multicolumn{2}{|c|}{ Male } & 11 & $10.7 \%$ \\
\hline & \multicolumn{2}{|c|}{ Female } & 92 & $89.3 \%$ \\
\hline \multirow[t]{2}{*}{ Age } & \multicolumn{2}{|c|}{$18-30$} & 67 & $65.0 \%$ \\
\hline & \multicolumn{2}{|l|}{$>30$} & 36 & $35.0 \%$ \\
\hline \multirow{3}{*}{ Matrimonial Status } & \multicolumn{2}{|c|}{ Single } & 44 & $42.7 \%$ \\
\hline & \multicolumn{2}{|c|}{ Married } & 53 & $51.5 \%$ \\
\hline & \multicolumn{2}{|c|}{ Divorced } & 6 & $5.8 \%$ \\
\hline \multirow[t]{2}{*}{ Social Class } & \multicolumn{2}{|c|}{ Medium Class } & 94 & $91.3 \%$ \\
\hline & \multicolumn{2}{|c|}{ High Class } & 9 & $8.7 \%$ \\
\hline \multirow{3}{*}{ Occupation } & \multicolumn{2}{|c|}{ Studying } & 16 & $15.5 \%$ \\
\hline & \multicolumn{2}{|c|}{ Working } & 63 & $61.2 \%$ \\
\hline & Unem & & 24 & $23.3 \%$ \\
\hline Rate of visit & Once & & 5 & $4.9 \%$ \\
\hline & Sever & a week & 6 & $5.8 \%$ \\
\hline & $1-2$ tir & onth & 48 & $46.6 \%$ \\
\hline & Once & months & 3 & $2.9 \%$ \\
\hline & Once & months & 2 & $1.9 \%$ \\
\hline & Once & months & 2 & $1.9 \%$ \\
\hline & On oc & only & 37 & $35.9 \%$ \\
\hline Spending for a treatment & $<\$ 50$ & & 8 & $7.8 \%$ \\
\hline & $\$ 50-\$$ & & 18 & $17.5 \%$ \\
\hline & $\$ 100-$ & & 50 & $48.5 \%$ \\
\hline & $>\$ 500$ & & 27 & $26.2 \%$ \\
\hline Type of Service Purchased & Hair $\mathrm{F}$ & & 86 & $40.4 \%$ \\
\hline & Facial & & 49 & $23.0 \%$ \\
\hline & Manic & licure & 21 & $9.9 \%$ \\
\hline & Cosm & & 40 & $18.8 \%$ \\
\hline & Body & & 16 & $7.5 \%$ \\
\hline & & Dermatology & 1 & $1.0 \%$ \\
\hline & Other & Hair Dressing & 1 & $1.0 \%$ \\
\hline Beauty Center & & Frequency & & Percentage \\
\hline ABC Dbayeh BC & & 1 & & $1.0 \%$ \\
\hline Al Markaziah Clinic & & 2 & & $1.9 \%$ \\
\hline Ashrafiyeh BC & & 2 & & $1.9 \%$ \\
\hline Beauty Care Hazmieh & & 1 & & $1.0 \%$ \\
\hline Beauty Spa Cure & & 2 & & $1.9 \%$ \\
\hline CK Beauty & & 1 & & $1.0 \%$ \\
\hline Clarins & & 3 & & $2.9 \%$ \\
\hline Cosma Baakline BC & & 2 & & $1.9 \%$ \\
\hline Derma Med & & 5 & & $4.9 \%$ \\
\hline Derma Pro & & 2 & & $1.9 \%$ \\
\hline Esthetique Maro & & 1 & & $1.0 \%$ \\
\hline Filiforme BC & & 2 & & $1.9 \%$ \\
\hline Hamade BC & & 1 & & $1.0 \%$ \\
\hline Herez Beauty Center & & 1 & & $1.0 \%$ \\
\hline Jane Nassar Beauty Clinic & & 25 & & $24.3 \%$ \\
\hline Laurance \& Issam & & 1 & & $1.0 \%$ \\
\hline Malla BC & & 4 & & $3.9 \%$ \\
\hline Nail Couture & & 2 & & $1.9 \%$ \\
\hline $\mathrm{NuYu}$ & & 6 & & $5.8 \%$ \\
\hline Pace et Luce & & 1 & & $1.0 \%$ \\
\hline Roland Kassis & & 2 & & $1.9 \%$ \\
\hline Seif Beauty Clinic & & 9 & & $8.7 \%$ \\
\hline Silhouette Laser Center & & 1 & & $1.0 \%$ \\
\hline Silkor & & 24 & & $23.3 \%$ \\
\hline Skin Tech & & 1 & & $1.0 \%$ \\
\hline Sura's Beauty Lounge & & 1 & & $1.0 \%$ \\
\hline Total & & 103 & & $100.0 \%$ \\
\hline
\end{tabular}




\subsubsection{Gender of Respondents}

The sample population contained both genders, consisting of $10.7 \%$ male, and $89.3 \%$ female. The female gender was not surprisingly the higher proportion, since females are more inclined to purchase beauty services than men. This confirms that the customers of beauty centers are mostly females. Men comprise only a small portion of the population, and this could be due to cultural taboos or certain perceptions of gender roles that may impinge on a man's likelihood to visit to a beauty center for beauty services. Although Beirut is a contemporary city, the customers who visit beauty centers are still mostly females.

\subsubsection{Age of Respondents}

The sample population contained $65 \%$ of people between the age of 18 and 30 , and $35 \%$ of people over the age of 30 . This sample was representative because people who seek beauty services are typically grown adults, above 18. The population above the age of 30 represent those who purchase beauty services with the desire to "look young", which is an essential quality one must preserve as a modern-day Lebanese (Tabeek, 2015).

\subsubsection{Matrimonial Status of Respondents}

In terms of the matrimonial status of the sample population, $42.7 \%$ were single, $51.5 \%$ were married, and $5.8 \%$ were divorced. This shows that those who desire to maintain their beauty are mostly either married or single, since physical appearance and attractiveness is of big importance to people in that kind of stage of life.

\subsubsection{Social Class and Consumption}

The social class of the sample population comprised of $91.3 \%$ medium-class and $8.7 \%$ high-class. For the sample's occupation status, $61.2 \%$ were working, $15.5 \%$ were studying, and $23.3 \%$ were unemployed. Therefore, it is presumable that the majority of the sample population could afford beauty services, which are typically expensive. Spending on beauty services makes up a large fraction of a customer's personal expenses, simultaneously with the frequency of their visits to obtain a treatment. In terms of the sample's frequency of visits to the beauty center, the majority (46.6\%) visit a beauty center $1-2$ times a month, and on occasion (35.9\%) The rest of the sample, being 5.8\% visit several times a week, $5 \%$ once a week, $3 \%$ once every 2 months, $2 \%$ once every 3 months, and $2 \%$ once every 4 months. The majority of the sample population, being $48.5 \%$, spend between $\$ 100$ and $\$ 500$ on a single treatment. At the same time, $26.2 \%$ spend more than $\$ 500,17.5 \%$ spend between $\$ 50$ and $\$ 100$, and $7.8 \%$ spend less than $\$ 50$. While beauty centers offer multiple services, the most common type of service purchased by the sample population was hair-removal, holding $40.4 \%$, followed by facials at $23 \%$, and cosmetic treatments at $18.8 \%$. Services like manicures and pedicures were purchased by $9.9 \%$, body treatment was $7.5 \%$, and hairdressing and dermatology were $0.5 \%$ of the sample population.

\subsubsection{Beauty Centers Involved}

In terms of the beauty centers visited, the majority of the sample population were customers of Jane Nassar consisting of $24 \%$, and $23 \%$ were customers of Silkor. Customers of Seif Beauty Clinic consisted of $8.7 \%$, NuYu $5.8 \%$, Derma Med 4.9\%, and Malla BC 3.9\%, and Clarins at 2.9\%. The rest of the population were dispersed among other beauty centers in Beirut, making up less than $2 \%$ of the population, including Centers like: $\mathrm{ABC}$ Dbayeh BC, Al Markaziah Clinic, Ashrafiyeh BC, Beauty Care Hazmieh, Beauty Spa Cure, CK Beauty, Cosma Baakline BC, Derma Pro, Esthetique Maro, Filiforme BC, Hamade BC, Herez Beauty Center, Laurance \& Issam, Nail Couture, Pace et Luce, Roland Kassis, Silhouette Laser Center, Skin Tech, Sura's Beauty Lounge.

\subsubsection{Descriptive Findings on the Implementation of CRM in SMEs}

Response frequencies are summarized below in Table 3 to illustrate the extent to which CRM was implemented in beauty centers. The results tabulated are from the customer's perspective. Each variable in the questionnaire contained several items (in the form of questions) that corresponded to CRM. Several questions were nominal-scale questions that contained direct "yes" or "no" responses, while some were likert-scale questions that contained responses on the scale of strongly disagree (1), disagree (2), neutral (3), agree (4) to strongly agree (5). Responses of (3) and below were perceived as "not implementing" CRM strategies, and responses of (4) and (5), were perceived as "implementing" CRM strategies. Table 3 follows, and illustrates what method SMEs use to contact customers during the interaction. With reference to table below, on average, $77 \%$ of customers indicated that SMEs implemented CRM, while 23\% indicated that SMEs did not. It devises the responses in detail, based on responses to items in the questionnaire, which pertain to the variables of the study. 
Table 3. The implementation of CRM in beauty centers

\begin{tabular}{|c|c|c|c|c|}
\hline \multicolumn{5}{|l|}{ Variable: Customer Experience } \\
\hline \multirow[t]{2}{*}{ Items } & \multicolumn{2}{|c|}{ Not Implementing } & \multicolumn{2}{|c|}{ Implementing } \\
\hline & Frequency & Percentage & Frequency & Percentage \\
\hline Reminder of appointment & 30 & $29.1 \%$ & 73 & $70.9 \%$ \\
\hline Follow-up after appointment & 50 & $48.5 \%$ & 53 & $51.5 \%$ \\
\hline Promotion Information & 26 & $25.2 \%$ & 76 & $73.8 \%$ \\
\hline Welcoming Reception & 17 & $16.5 \%$ & 86 & $83.5 \%$ \\
\hline Refreshing Ambiance & 15 & $14.6 \%$ & 88 & $85.4 \%$ \\
\hline Generous Hospitality & 27 & $26.3 \%$ & 76 & $73.8 \%$ \\
\hline Help Available & 17 & $16.5 \%$ & 86 & $83.5 \%$ \\
\hline \multicolumn{5}{|l|}{ Variable: Employee Behaviour } \\
\hline \multirow[t]{2}{*}{ Items } & \multicolumn{2}{|c|}{ Not Implementing } & \multicolumn{2}{|c|}{ Implementing } \\
\hline & Frequency & Percentage & Frequency & Percentage \\
\hline Friendly Employees & 15 & $14.6 \%$ & 88 & $85.4 \%$ \\
\hline Polite Employees & 8 & $7.8 \%$ & 95 & $92.2 \%$ \\
\hline Needs Listened & 12 & $11.7 \%$ & 91 & $88.3 \%$ \\
\hline Preferences Known & 20 & $19.4 \%$ & 83 & $80.6 \%$ \\
\hline Quick Response & 19 & $18.5 \%$ & 84 & $81.6 \%$ \\
\hline Knowledge of Equipment & 12 & $11.7 \%$ & 91 & $88.3 \%$ \\
\hline Expert in work & 11 & $10.7 \%$ & 92 & $89.3 \%$ \\
\hline Cooperative Employees & 24 & $23.3 \%$ & 79 & $76.7 \%$ \\
\hline \multicolumn{5}{|l|}{ Variable: Value Proposition } \\
\hline \multirow[t]{2}{*}{ Items } & \multicolumn{2}{|c|}{ Not Implementing } & \multicolumn{2}{|c|}{ Implementing } \\
\hline & Frequency & Percentage & Frequency & Percentage \\
\hline Fair Price & 28 & $27.2 \%$ & 75 & $72.8 \%$ \\
\hline Product Quality & 12 & $11.7 \%$ & 91 & $88.3 \%$ \\
\hline Equipment Quality & 15 & $14.6 \%$ & 88 & $85.4 \%$ \\
\hline Service to Preference Fit & 21 & $20.4 \%$ & 82 & $79.6 \%$ \\
\hline Fulfillment of Needs & 21 & $20.4 \%$ & 82 & $79.6 \%$ \\
\hline \multicolumn{5}{|l|}{ Variable: Relationship Development } \\
\hline \multirow[t]{2}{*}{ Items } & \multicolumn{2}{|c|}{ Not Implementing } & \multicolumn{2}{|c|}{ Implementing } \\
\hline & Frequency & Percentage & Frequency & Percentage \\
\hline Maintaining Record of Personal Info. & 6 & $5.8 \%$ & 97 & $94.2 \%$ \\
\hline Maintaining Record of Visits & 7 & $6.8 \%$ & 96 & $93.2 \%$ \\
\hline Presence of a loyalty-card program & 86 & $83.5 \%$ & 17 & $16.5 \%$ \\
\hline Feedback request & 18 & $17.5 \%$ & 84 & $81.6 \%$ \\
\hline Complaint handled without delay & 14 & $28.0 \%$ & 36 & $72.0 \%$ \\
\hline Satisfaction of solution for complaint & 18 & $36.7 \%$ & 31 & $63.3 \%$ \\
\hline
\end{tabular}

\section{Discussion}

According to the customer experience variable, over $70 \%$ of the sample population perceived that beauty centers implemented CRM strategies. However, there was only one item in this category that yielded a lower rate than the rest, which was "follow-up after appointment". The result indicates that $51.5 \%$ of the sample population was contacted by the beauty center for a follow-up after their appointment, while $48.5 \%$ were not contacted. According to Scarborough (2011), a business' effort to follow-up with a customer shows sincerity, confidence and an honest desire to build an ongoing relationship. Following-up is a relevant element of customer interaction, because customers will feel special and appreciative, and the relationship-building will be memorable for both parties. However, the reason that some SMEs fell behind on the follow-up aspect could be due to a lack of time, or lack of awareness. However, regular follow-up routines can open up potential for repeat business and therefore more profit. This is a relevant component of CRM to consider.

In terms of the employee behaviour, value proposition, and relationship development variables, the majority of the sample population, approximately $80 \%$ and above, perceived the beauty center implemented CRM strategies. It is apparent that beauty centers possess the suitable skills and competencies, found in their employees. As employees are in direct contact with the customers, it is crucial that owners ensure that the behaviour of their employees complies with the workplace initiatives. Also, it is apparent that the beauty centers have a decent value proposition for their customers in effort of ensuring satisfaction and continuous business. 
However, for one item from the relationship development variable, $83.5 \%$ of the sample population responded that the "presence of a loyalty-card program" was not implemented. From that population, $24.3 \%$ responded that a loyalty-card was not present, and 59.2\% was not aware whether a loyalty-card program existed. While only $16.5 \%$ declared that the beauty center had a loyalty card program, this result shows that beauty centers have not yet grasped the importance of this element in the development of customer relationships. Owners of beauty centers should incorporate more loyalty-card programs because it is a strategy that would motivate customers to conduct more transactions and it increases their commitment while accumulating assets to do so. However, according to our results, in the Lebanese context it appears that the tool is unpopular among small businesses. The reason could be based under the assumption that some business owners cannot afford to give incentives to customers, such as free products or services that are otherwise very expensive. However, if the potential benefits are realized, the business could benefit from having a competitive advantage in the market.

CRM applies not only people and processes, but also technology, and therefore it was important for the researcher to discover which methods of interaction are beauty-centers using, as depicted in Table 4. The sample population reported that the Telephone was the most common source of contact, compared to E-mail or SMS, for matters such as: reminders, follow-ups, promotions, complaints, and feedback. For situations that were more profound, such as promotions, reporting of complaints, and request for feedback, beauty centers used face-to-face contact the most. E-mail, SMS, and social media were the least used. This outcome was expected because the face-to-face method is typically the most cost-effective and intimate source of interaction for SMEs. Some SMEs in Lebanon may not be equipped with the right technology, or CRM systems, that can perform automation. Hence, the economical and more effective alternative is face-to-face. For instance, when informing a customer about a promotion, telling them face-to-face makes them feel like it is an exclusive offer tailored to their needs. Reporting a complaint and face-to-face is a way of handling matters promptly and in private. Moreover, approaching the customer face-to-face to request their feedback also boosts the customer's confidence in the business, to which their contribution is considered important. The use of these certain methods indicates that SMEs are implementing the most efficient CRM strategies for their business in order to deliver value and the right solutions to customers.

Table 4. The methods of interaction used by SMEs

\begin{tabular}{llllllll}
\hline \multirow{2}{*}{ Activity } & \multicolumn{2}{l}{ Method of Interaction } \\
\cline { 2 - 8 } & Face-to-Face & Telephone & Email & SMS & Website & Social Media & Billboards \\
\hline Reminder of appointment & $\mathrm{n} / \mathrm{a}$ & $58.3 \%$ & 0 & $21.4 \%$ & $\mathrm{n} / \mathrm{a}$ & $\mathrm{n} / \mathrm{a}$ & $\mathrm{n} / \mathrm{a}$ \\
Follow-up after appointment & $\mathrm{n} / \mathrm{a}$ & $45.6 \%$ & $0 \%$ & $12.6 \%$ & $\mathrm{n} / \mathrm{a}$ & $\mathrm{n} / \mathrm{a}$ & $\mathrm{n} / \mathrm{a}$ \\
Promotion Information & $39.8 \%$ & $24.3 \%$ & $0 \%$ & $34.0 \%$ & $0 \%$ & $31.1 \%$ & $21.4 \%$ \\
Report of Complaint & $36.9 \%$ & $11.7 \%$ & $0 \%$ & $1.9 \%$ & $0 \%$ & $0 \%$ & $\mathrm{n} / \mathrm{a}$ \\
Request of Feedback & $69.9 \%$ & $16.5 \%$ & $0 \%$ & $0 \%$ & $0 \%$ & $1.0 \%$ & $\mathrm{n} / \mathrm{a}$ \\
\hline
\end{tabular}

\section{Conclusion}

Overall, it is apparent that SMEs in Lebanon implement CRM to an impressively good extent. This outcome was unexpected because several considerations about the Lebanese context are far from prospects of development. Lebanon spent many years in civil war, and many years afterwards in recovery. Considerable efforts were spent to support the private sector as the main engine of growth in the Lebanese economy; however, SMEs in Lebanon still operate in a complex environment composed of moderate-to-poor infrastructure setups, economic uncertainty, and slow business activity (Inventis, 2014). While the environment is challenging and vulnerable to changes, it is composed of heavy competition from small and large rivals in the beauty industry, locally and globally. Nevertheless, since Lebanon is a touristic country, it is known to have a contemporary culture that places great emphasis on physical appearance, and customers nowadays, have become empowered and have versatile demands. Therefore, as a consequence, entrepreneurs are forced be in harmony with changing demands over time and must break traditional means of doing business in order to survive in the market. This means to transition from traditional marketing initiatives to new, relationship-oriented strategies, such as CRM. Initially, investments in CRM strategies were more apparent in banks, and involved transactional processes (Peelen \& Beltman, 2013). Evidently, SMEs in Lebanon have transitioned to be more customer-centric while using the most effective methods. Lebanon possesses the prerequisites for economic growth, such as educated entrepreneurs that have a passion to maximize opportunities, a mature financial industry with global members, talented people with multinational experience and a unique culture among the Arab region. Hence, the role of CRM has expanded throughout many enterprises with prospects of growth for business owners who have 
thought beyond just profit, and have more willingly recognized the importance of securing customer loyalty, and long-term relationships for greater returns.

The limitation of this study was its reliance on snow-ball sampling. The previously mentioned limitation gives attention to different avenues of research. These avenues concern the extension of this research and application of the model to other contexts. Lastly, qualitative techniques could be incorporated to supplement quantitative connotations.

\section{References}

Analoui, F., \& Karami, A. (2003). Strategic Management in Small and Medium Enterprises. London: Thomson Learning.

Buttle, F. (2004). Customer Relationship Management; concepts and tools. Elsevier Ltd. https://doi.org/10.4324/9780080472430

Inventis. (2014). Lebanon SME Strategy, a Roadmap to 2020. Ministry of Economy and Trade. Retrieved from http://www.economy.gov.lb/public/uploads/files/6833_5879_4642.pdf

Kirmaci, S. (2012). Customer Relationship Management and Customer Loyalty, A Survey in the Sector of Banking. International Journal of Business and Social Science, 3, 1-10.

Peelen, E., \& Beltman, R. (2013). Customer Relationship Management. United Kingdom: Pearson.

Long, C. S., Khalafinezhad, R., Ismail, W. K. W., \& Rasid, S. Z. A. (2013). Impact of CRM factors on customer satisfaction and loyalty. Asian Social Science, 9(10), 247. https://doi.org/10.5539/ass.v9n10p247

MSME database. (2006). World Bank.

Ndubisi, N. O., Wah, C. K., \& Ndubisi, G. C. (2007). Supplier-Customer Relationship Management and Customer Loyalty: The Banking Industry Perspective. Journal of Enterprise Information Management, 20(2), 222-236. https://doi.org/10.1108/17410390710725797

O zgener, S., \& I raz, R. (2006, January 1). Customer Relationship Management in Small-Medium Enterprises: The case of Turkish tourism industry. Tourism Management, 27(6), 1356-1363.

Peelen, E., \& Beltman R. (2013). Customer Relationship Management. United Kingdom: Pearson.

Reijonen, H., \& Laukkanen, T. (2010, January 1). Customer Relationship Oriented Marketing Practices in SMEs. Marketing Intelligence \& Planning, 28(2), 115-136. https://doi.org/10.1108/02634501011029646

Rostek, K. (2015). Benchmarking Collaborative Networks: A Key to SME Competitiveness. Berlin: Springer. https://doi.org/10.1007/978-3-319-16736-7

Scarborough, N. M. (2011). Essentials of Entrepreneurship and Small Business Management. New Jersey: Pearson.

Shen, J. C., \& Russell, K. H. C. (2007, January 1). The Effects of Customer Relationship Management Practices and Multiple-Channels on Customer Loyalty in Financial Services. Asia Pacific Management Review, 12, $171-180$.

Soliman, H. S. (2011). Customer Relationship Management and Its Relationship to the Marketing Performance. International Journal of Business and Social.

Tabeek, M. (2015). Lebanese Women Feel Inner Beauty Not Enough. Al Monitor. Retrieved from http://www.al-monitor.com/pulse/originals/2015/02/lebanon-beauty-standards women-plastic-surgery.html

Zablah, A. R., Bellenger, D. N., \& Johnston, W. J. (2004, January 1). An Evaluation of Divergent Perspectives on Customer Relationship Management: Towards a Common Understanding of an Emerging Phenomenon. Industrial Marketing Management, 33(6), 475-489. https://doi.org/10.1016/j.indmarman.2004.01.006

\section{Copyrights}

Copyright for this article is retained by the author(s), with first publication rights granted to the journal.

This is an open-access article distributed under the terms and conditions of the Creative Commons Attribution license (http://creativecommons.org/licenses/by/4.0/). 